\title{
COMPARING THE OUTCOMES OF A MODIFIED TECHNIQUE USING A SPATULATED UMBILICAL CORD PATCH FOR A SCARLESS PRIMARY REPAIR OF GASTROSCHISIS WITH OTHER TECHNIQUES FOR PRIMARY CLOSURE, A MULTICENTER EXPERIENCE
}

\author{
Sherif M Mansour*, Osama A El-Naggar*, Thomas T Tsang**, \\ Mosad M El-Behery*, Mohamed S El-Debeiky* and Mohamed S El-Sherbeiny*
}

\begin{abstract}
* Department of Paediatric
Surgery, Ain Shams

University Cairo, Egypt

** Consultant of Paediatric

Surgery, Norfolk and Norwich University Hospital

Corresponds:

Sherif M Mansour
\end{abstract}

E.male:

dr.sherif.mamdouh@hotm ail.com

Tel.: +201006180690

Received: 3/3/2019

Accepted: 27/3/2019

\begin{abstract}
Background: The goal of the surgical management of gastroschisis is to return the bowel into the abdomen without jeopardizing the viscera. Primary fascial closure (PFC) was historically favored due to improved outcomes.
\end{abstract}

Aim of the work: To prospectively analyse the outcomes of primary closure of gastroschisis using Spatulated Umbilical Cord (SUC) technique, and compare with the retrospectively-collected outcomes of patients who underwent PFC.

Patients and Methods: this pilot interventional case-control study was conducted at the Departments of Paediatric Surgery at Norfolk and Norwich University Hospital in UK and at Ain-Shams University Hospitals in Egypt during the period from February 2017 to February 2019. The "Study" group was a prospective cohort of patients with gastroschisis; in whom SUC closure technique was used. The control group was a retrospective cohort of patients; who underwent primary fascial closure. Outcome measures were success rates, post-operative ventilation, days of parenteral nutrition, time to full enteral feeds and complications.

Technique: The SUC patch involved the following: the amnion layer is opened from the base at 9 O'clock position, the Wharton's jelly exposed and 'spatulated' using longitudinal incisions and then secured as a patch over the defect.

Results: Whereas PFC was successful in all patients $(n=10)$, SUC patch technique was successful in $77.8 \%(n=9)$. The duration of mechanical ventilation was statistically significantly shorter in the control group compared to the study group (1.75vs4.0 days). Time-tostart or achieve goal enteral feeding was longer in patients with SUC patch technique, but not statistically significant. Regarding complications, 2 patients in the study group needed re-laparotomy after development of abdominal hypertension. Intestinal obstruction occurred in one patient, and one patient had a persistent umbilical hernia. One patient in the control group had a laparotomy for bowel obstruction and one patient required the repair of a persistent umbilical hernia.

Conclusion: Primary closure of gastroschisis using SUC is safe, feasible, cost-effective and with comparable outcomes to other wellestablished techniques. 
Keywords: Gastroschisis - SUC patch - outcomes

\section{INTRODUCTION:}

Gastroschisis is a congenital defect in the abdominal wall. It occurs in 1 in 4,000 live births. There has been a significant worldwide increase in the incidence of gastroschisis in all age groups over the past two decades ${ }^{(1)}$.

The first clear description of a gastroschisis was by Calder in $1733^{(2)}$. Hey, in 1775, described a newborn with "the whole of the small intestine, lying upon the belly, not enclosed in any sac"(3). The first survivors were reported by Vissick ${ }^{(4)}(1873)$, which in retrospect was a ruptured omphalocele minor, and Fear ${ }^{(5)}$ (1878).

Gastroschisis is an isolated defect in $95 \%$ of cases. The main problem is not the abdominal wall defect itself, but the associated bowel complications that occur because of the defect.

Advances in neonatal intensive care in developed countries have decreased mortality significantly; $<5 \%$ today ${ }^{(6)}$. Recent literature reports mortality rates of $30-80 \%$ in developing countries ${ }^{(7)}$.

The principles of management of gastroschisis are; first, to reduce the viscera safely and, second, to close the abdominal wall defect with an acceptable cosmetic appearance. Operative primary reduction with sutured fascial defect closure has become the standard initial surgical strategy, whereas staged reduction using preformed silo is frequently used as a rescue strategy when reduction is deemed unsafe or physically impossible because of viscera abdominal disproportion.

The drawbacks to the sutured closure method are that aggressive manipulation and reduction of the bowel, followed by closure of the abdominal wall under tension, can cause high intra-abdominal pressures that impact ventilator mechanics, requiring prolonged intubation and use of narcotic analgesics. In addition, the increased intraabdominal pressure, along with narcotic effects, can contribute to an ileus, prolonging time to full enteral feeds and increasing the length of hospitalization. In worst-case scenarios, an acute abdominal compartment syndrome can develop, leading to bowel ischemia.

In 2004, Sandler and colleagues described a plastic sutureless abdominal wall gastroschisis closure where the defect was covered with a remnant of the umbilical cord and a plastic occlusive dressing ${ }^{(8)}$.

In our study, we are developing a modified technique combining the advantages of both sutured and plastic closure techniques. We use a spatulated umbilical cord (SUC) patch to cover large defects in small babies who are not amenable to primary fascial closure. By this technique, we are trying to minimize the risk of developing abdominal compartmental syndrome and paralytic ileus owing to increased intra-abdominal pressure. Another advantage over plastic closure is that there is no need to use any dressings, with decreased risk of developing wound related complications.

\section{MATERIAL AND METHODS:}

\section{Participants}

A pilot interventional case control clinical trial was conducted at the Department of Paediatric Surgery at Norfolk and Norwich University Hospital (NNUH) NHS Foundation Trust in UK and Department of Paediatric Surgery at Ain Shams University Hospitals (ASUH) in Egypt during the period from February 2017 to February 2019. The "Study" group; which included 9 patients, was a prospective cohort of patients born with uncomplicated 
gastroschisis; on whom primary surgical closure using SUC technique was used. The "Control" group; which included 10 patients, was a retrospective cohort of patients born with uncomplicated gastroschisis; who underwent primary fascial closure using other techniques. All the patients born with complicated gastroschisis and/or the babies in whom primary closure using SUC technique was deemed unsafe were excluded from the study.

\section{Ethical considerations}

All the required clinical and ethical guidelines of both centers were followed. The study was approved by the Ethical Research Committee of both centers. Written informed consent is obtained before the procedure from one of the legal guardians of the patient.

\section{Methodology}

All the patients were operated upon by the senior surgeon.After anaesthesia, bowel decompression is achieved by gentle milking of the bowel; proximally then asking the anaesthetist to aspirate the nasogastric tube and distally after irrigating the bowel with low pressure rectal washouts. The bowel is assessed to rule out atresia. The eviscerated bowel is then reduced into the abdominal cavity by applying gentle sustained pressure to avoid bowel perforation and creating mesenteric defects. If the abdominal cavity is too small, manual gentle stretching of the abdominal wall is done to help it accommodate the bowel. The size of the defect is then measured. In our study, the size ranged between 2 to 5.5 centimetres, which was deemed not suitable for safe fascial closure. Before preparing the umbilical cord patch, simulation of primary fascial closure is first tried. This is done by approximating the edges of the recti and asking the anaesthetist to monitor the ventilation pressures. If there is a slight or no increase, then primary fascial closure is performed. Only when there is a marked rise in the ventilatory settings, then closure by the umbilical cord flap technique is applied.

\section{The Spatulated Umbilical Cord (SUC) patch is prepared as follow:}

1. The size of the defect is first measured. Then, longitudinal marking of the umbilical cord; by a sterile marker pen, starting at 9 o'clock position as a guide for the incision site (Figure 1). The amnion layer is then incised from the base using tenotomy scissors or the diathermy, for a length matching the skin defect.

2. The Wharton's jelly is exposed and 'spatulated' by making fine longitudinal incisions using sharp dissection (black curved lines in the figure), leaving the umbilical vessels intact. Release incisions at the lateral edges of the base of the cord help to make the spatulation more efficient (black circles in the figure). The extent of the spatulation is determined by the size of the defect (Figure 2).

3. The spatulated cord is secured as a patch over the defect; using interrupted 5/0 PDS (Ethicon ${ }^{\mathrm{TM}}$ ) sutures. The sutures are taken between the edges of the patch and the full thickness of the adjacent abdominal wall skin, sparing the muscles and the fascia. This is best to be accomplished by taking alternating interrupted sutures in such a way that one suture is taken at the upper border of anastomosis, then the following suture to be taken at the lower border and so on until the whole patch is secured. An adequate length of the umbilical cord is left intact in case it is needed later (Figure 3).

Postoperatively, a simple Vaseline dressing is applied om the suture line for 48 hours. Postoperative intravenous antibiotics are given for 5 days. Patients had over-night ventilation; if needed, following operation and extubated as per protocols. PICC line or a surgically inserted central line is used to administer TPN for the neonate until full enteral nutrition is established. The nasogastric tube is aspirated 4 hourly and the 


\section{Sherif M Mansour, et al.,}

aspirate is measured and documented. Laboratory investigations; including full blood count and blood chemistry, are done day 1 post-operatively then repeated as per the NICU protocols. Patients were discharged once full enteral nutrition is established and complete weaning of $\mathrm{PN}$ is achieved. Surveillance of the patients by regular follow up clinic appointments at 3 months, 6 months and 12 months, and then yearly follow up by the paediatric surgeon until patient is referred to a paediatric gastro-enterologist.

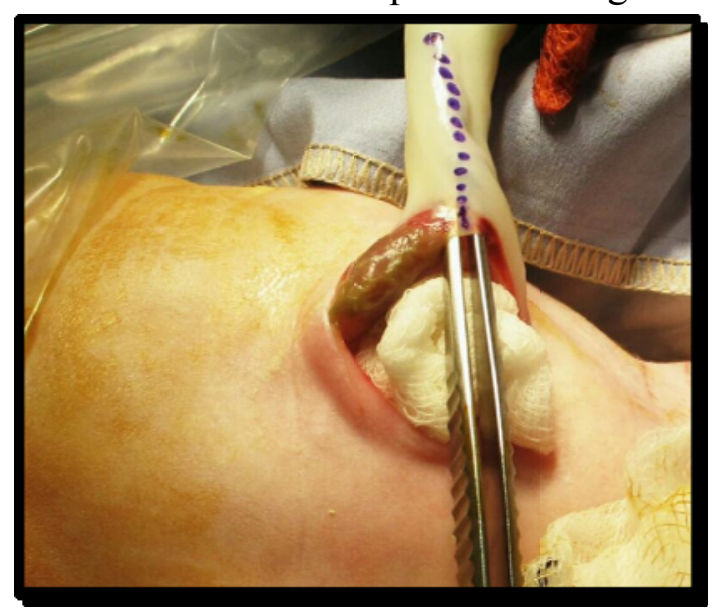

Figure 1: Longitudinal marking of the incision on the cord

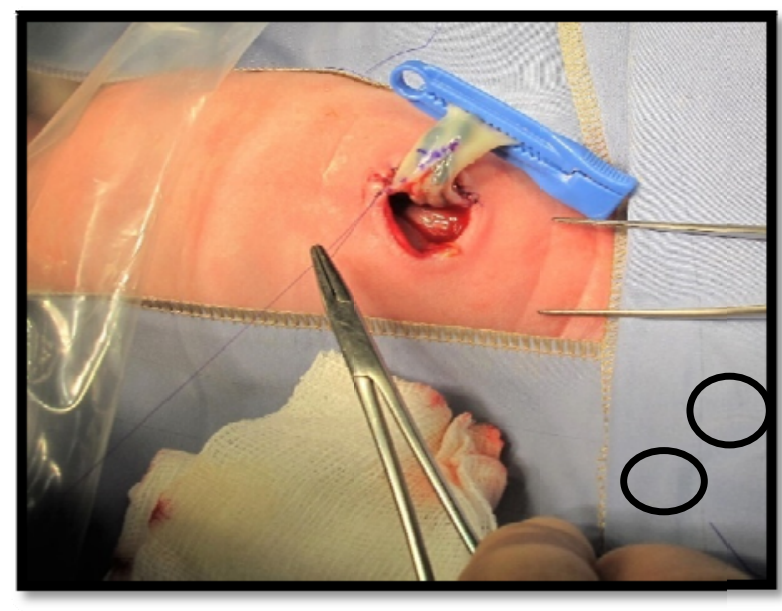

Figure 3: Suturing of the patch to the skin by using interrupted 5/0 PDS sutures

\section{Statistical analysis:}

Data were analyzed using SPSS version 24.0 (SPSS Inc, Chicago, IL, USA). Data were analyzed on intention-to-treat basis. Parametric numerical data are presented as mean \pm standard deviation; whereas nonparametric numerical data are presented as median with interquartile range. Categorical

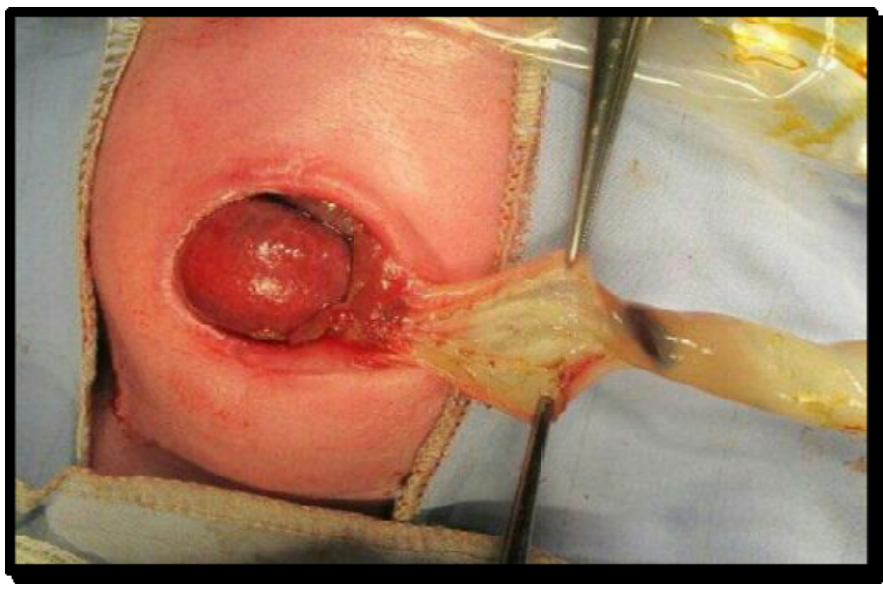

Figure 2: Spatulated umbilical cord (SUC) patch ready for suturing to skin defect

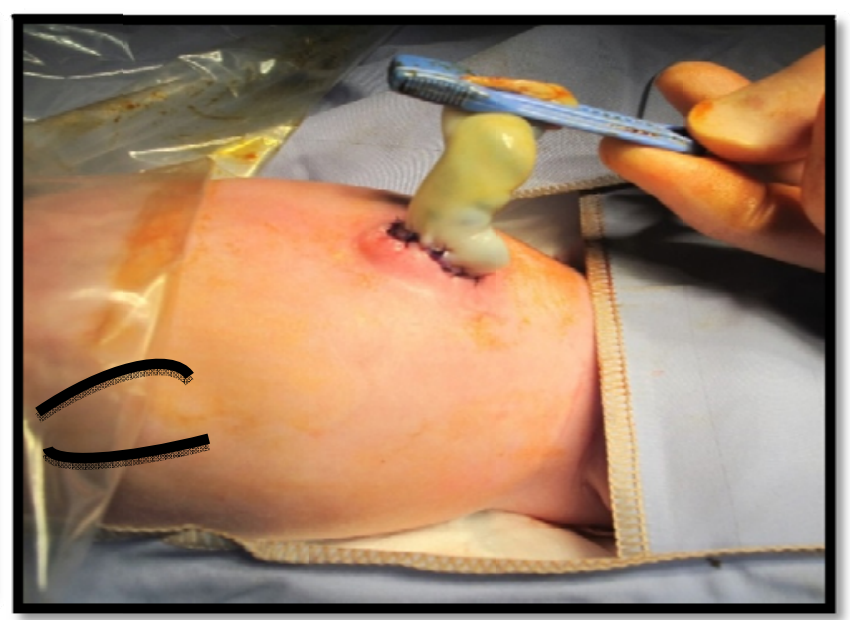

Figure 4: Final appearance of the secured patch over the defect

data are presented as number and percentage. Two group comparisons for numerical data was done using the Student $\mathrm{t}$ test for parametric data and using the MannWhitney test for non-parametric data. Categorical data were compared using Chisquare test or Fisher exact test. Significance level was set at $\mathrm{p} \leq 0.05$. 


\section{RESULTS:}

A total number of 19 patients were included in the study; 9 babies ( 7 from NNUH and 2 from ASUH) in the study group and 10 babies in the control group (from NNUH). It should be noted that owing to the small size of the study population, inferential statistical analysis would be of a limited power. Thus, in-depth descriptive analysis of various outcomes and associated risk factors was endorsed.

Analysis of the basic demographic and clinical characteristics of both study groups revealed the absence of statistically significant differences between both groups regarding gestational age, sex, mode of delivery, birth weight or incidence of meconium-stained/offensive liquor or eventful neonatal resuscitation (Table 1).

No significant differences were found between patients of the two groups regarding birth-theatre interval or size of abdominal defect.

Success of surgical procedure using spatulated umbilical cord patch technique or other primary fascial closure techniques was defined as definitive primary closure of abdominal wall defect without resorting to another secondary surgical intervention. Whereas other primary fascial closure techniques were successful in all patients, spatulated umbilical cord patch technique was successful in only $77.8 \%$. Although this estimated difference failed to reach a statistical significance implying the absence of difference in the success rate of both techniques.
Endotracheal intubation and invasive mechanical ventilation was not needed in one patient with the SUC patch technique; where bedside sedation was sufficient to complete the procedure successfully. Timeto-extubation; reflecting the degree of development of abdominal hypertension as well as the degree of lung maturity, was statistically significantly shorter in the control group compared to the SUC patch technique (1.75 vs 4.0 days respectively). Hazard ratio was calculated as 2.19 , i.e. at any given time, the probability of successful extubation with control techniques is approximately twice that with the SUC patch group. However, the variable of lung maturity was not considered. It should be noted that the number of preterm patients in the study group is more than the control group. (Diagram)

Although time-to-start and achieve goal enteral feeding was longer in patients with SUC patch technique compared to the control techniques, these differences failed to reach statistical analysis on Kaplan-Meier analysis. Caution should be noted with generalization of such finding due to the small sample size of the study. (Table 3)

No statistically significant differences were found between the patients of both groups regarding the incidence of the different surgical complications. Two patients in the SUC patch group needed relaparotomy after development of abdominal hypertension. Intestinal obstruction occurred in SUC patch group patient who developed abdominal hypertension and underwent siloreduction; and in another patient in the control group. (Table 3) 


\section{Sherif M Mansour, et al.,}

Table 1.Comparison between study groups regarding basic demographic, clinical and perinatal characteristics

\begin{tabular}{|c|c|c|c|}
\hline & SUC Patch Group & Control Group & $\mathbf{P}$ \\
\hline $\begin{array}{l}\text { Gestational age (wks) } \\
\text { Range } \\
\text { Mean } \pm \text { SD } \\
\text { Preterm }(\%)\end{array}$ & $\begin{array}{l}33.0-39.0 \\
36.0 \pm 2.0 \\
5(55.6 \%)\end{array}$ & $\begin{array}{l}33.0-38.0 \\
36.10 \pm 1.59 \\
4(40.0 \%)\end{array}$ & 0.91 \\
\hline $\begin{array}{l}\text { Sex } \\
\text { Male (\%) } \\
\text { Female (\%) }\end{array}$ & $\begin{array}{l}2(22.2 \%) \\
7(77.8 \%)\end{array}$ & $\begin{array}{l}5(50 \%) \\
5(50 \%)\end{array}$ & 0.34 \\
\hline $\begin{array}{l}\text { Mode of delivery } \\
\text { Vaginal delivery } \\
\text { Cesarean section }\end{array}$ & $\begin{array}{l}4(57.1 \%) \\
3(42.9 \%)\end{array}$ & $\begin{array}{l}7(70.0 \%) \\
3(30.0 \%)\end{array}$ & 0.64 \\
\hline Meconium-stained liquor (\%) & $1(11.1 \%)^{\mathrm{a}}$ & $0(0 \%)$ & 0.47 \\
\hline Offensive liquor (\%) & $1(11.1 \%)^{\mathrm{a}}$ & $0(0 \%)$ & 0.47 \\
\hline $\begin{array}{l}\text { Eventful neonatal } \\
\text { resuscitation (\%) }\end{array}$ & $1(11.1 \%)^{\mathrm{a}}$ & $0(0 \%)$ & 0.47 \\
\hline $\begin{array}{l}\text { Birth weight (gm) } \\
\text { Range } \\
\text { Mean } \pm \text { SD } \\
\text { Low birth weight (\%) }\end{array}$ & $\begin{array}{l}1800.0-2800.0 \\
2217.4 \pm 320.1 \\
7(77.8 \%)\end{array}$ & $\begin{array}{l}1515.0-3310.0 \\
2550.3 \pm 597.4 \\
4(40.0 \%)\end{array}$ & 0.15 \\
\hline \multicolumn{4}{|c|}{$\begin{array}{l}\text { a Patient no. } 3 \text { had a preterm emergency cesarean delivery at } 33^{+3} \text { weeks GA for a breech } \\
\text { labor in a primigravida. Liquor was meconium-stained with offensive odor. Following } \\
\text { delivery, she failed to commence spontaneous breathing. Gentle stimulation, positioning, } \\
\text { managing airway and oxygen, together with suction and tracheal suction for meconium } \\
\text { were utilized. This was followed by the use of facemask CPAP, facemask IPPV and } \\
\text { eventually intubation, cardiac compressions till } 6 \text { minutes. APGAR scores were } 2,5 \text { and } 9 \\
\text { at } 1,5 \text { and } 10 \text { minutes respectively. Cord venous blood gases revealed pH } 7.36, \text { PCO2 } 5.9 \\
\text { and BE - } 0.8 \text {. It should be noted that this event didn't seem to affect the subsequent good } \\
\text { course thereafter. }\end{array}$} \\
\hline
\end{tabular}

Table 2. Comparison between the study groups regarding nutritional outcomes.

\begin{tabular}{|l|c|c|c|}
\hline & SUC Patch Group & Control Group & P \\
\hline $\begin{array}{l}\text { Time-to-start enteral } \\
\text { feeding (days) } \\
\text { Median (95\%CI) }\end{array}$ & $8.0(8.0-11.0)$ & $7.0(6.0-9.0)$ & 0.42 \\
\hline Hazard ratio (95\%CI) ${ }^{\text {a }}$ & \multicolumn{2}{|c|}{$1.39(0.55-3.51)$} & \\
\hline $\begin{array}{l}\text { Time-to-reach goal } \\
\text { enteral feeding (days) } \\
\text { Median (95\%CI) }\end{array}$ & $19.0(14.0-48.0)$ & $17(13.0-34.0)$ & 0.36 \\
\hline Hazard ratio (95\%CI) $^{\text {a }}$ & \multicolumn{2}{|c|}{$1.50(0.58-3.89)$} & \\
\hline
\end{tabular}




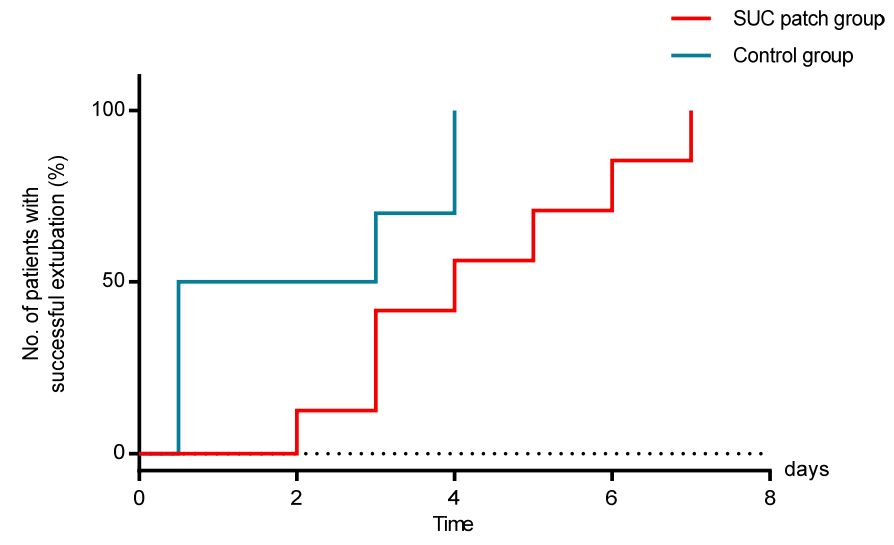

Diagram. Kaplan-Meier analysis for time-to-extubate in SUC patch and control groups.

Table 3. Comparison between study groups regarding incidence of surgical complications.

\begin{tabular}{|l|c|c|c|}
\hline & SUC Patch Group & Control Group & P \\
\hline Abdominal hypertension & $2(22.2 \%)$ & $0(0 \%)$ & 0.21 \\
Conservative management & $0(0 \%)$ & $0(0 \%)$ \\
Return to theatre & $2(22.2 \%)$ & $0(0 \%)$ & \\
\hline Sepsis & $2(22.2 \%)$ & $2(20 \%)$ & 0.99 \\
Surgical site infection & $2(22.2 \%)$ & $2(20 \%)$ & \\
Necrotizing enterocolitis & $1(11.1 \%)$ & $1(10 \%)$ & \\
Others & $1(11.1 \%)$ & $1(10 \%)$ & 0.99 \\
\hline Intestinal obstruction & $1(11.1 \%)$ & $0(0 \%)$ & 0.22 \\
\hline Metabolic complications & $1(11.1 \%)$ & $0(0 \%)$ & \\
Isolated acute kidney injury & $1(11.1 \%)$ & $0(0 \%)$ & \\
Jaundice & $1(11.1 \%)$ & $0(0 \%)$ & \\
Hyponatremia & $2(22.2 \%)$ & $1(10 \%)$ & \\
Hypophosphatemia & $0(0 \%)$ & $1(10 \%)$ & \\
\hline Remote complications & $0(0 \%)$ & $1(10 \%)$ & \\
Umbilical hernia & $1(11.1 \%)$ & $2(20 \%)$ & 0.49 \\
Adhesional band & $0(0 \%)$ & $1(10 \%)$ & \\
Persistent umbilical suture & $1(11.1 \%)$ & $0(0 \%)$ & 0.47 \\
\hline Nutritional complications & & & \\
Slow establishing weight gain & & & \\
Constipation & & & \\
\hline Mortality & & & \\
\hline
\end{tabular}

\section{DISCUSSION:}

Paediatric surgery division of Ain Shams University Hospital is one of the largest tertiary care paediatric surgery centres in Egypt. With limited resources, we are continuously trying to improve our service. Our main aim in this study was to try to generate a generic neonatal surgical care intervention; which is simple, costeffective and will help to improve our outcomes.
The surgical management of gastroschisis varies widely. The most common interventions in high income countries are primary closure in the operating room or use of a preformed silo with gradual intestinal reduction and delayed closure, often at the cot-side without general anaesthetic $^{(9)}$.

In this pilot study, we evaluated the efficacy of a modified technique for primary closure of gastroschisis using a spatulated 


\section{Sherif M Mansour, et al.,}

umbilical cord patch. The autogenous umbilical stump is always at hand; the patch is nontoxic, non antigenic and, above all, safe and cost-free. The umbilical patch with a sterile inner surface that contains Wharton's jelly (WJ) covering the defect and lying on the intestine has given satisfactory or even excellent results. At the same time, WJ facilitates maximal regeneration of skin, adipose, connective, and contractile cells. On the other hand, this natural membrane served to prevent adhesions between the underlying bowel and the epithelialized umbilical patch.

Despite the small sample size; the current study is considered the first study to compare the primary closure of gastroschisis using SUC and direct fascial closure. Due to the pilot nature of this study, our aim was not to produce statistically significant results between the 2 study groups as much as that we wanted to present and introduce this modified technique and evaluate whether it has comparable results to other wellestablished techniques.

According to our results, no statistically significant differences between both study groups regarding demographic and clinical characteristics. We found more female patients than male. Bradnock $\mathrm{T} J$ et al found same $^{(10)}$ but Owen A et al. found opposite $^{(11)}$.

In our study, the mean duration from birth until time of surgical intervention of patients in the study group was about 5.4 hours (range: 1-24 hours). There were 2 patients who underwent ex-utero transfer to our tertiary centre (6 hours and 24 hours).

Whereas primary fascial closure techniques were successful in all patients, spatulated umbilical cord patch technique was successful in $77.8 \%$ (7/9 patients), i.e. it failed in 2 patients. This highlights the importance of the proper selection of the technique tailored to each patient. Moreover, one should have a very low threshold for conversion to silo closure if there are any difficulties during the trial of primary reduction.

Apart from the 2 patients who developed compartmental syndrome and needed a relaparotomy, none of the patients in the study group showed any breaking down of the patch or leakage of peritoneal fluid. The SUC patch and the rest of the cord were left exposed after 2 days and allowed to dry and fall off as in any normal newborn. Umbilical sepsis was not seen in any of these patients.

In the current study, duration of mechanical ventilation was statistically significantly shorter in the control group compared to the SUC patch technique (1.75 vs 4.0 days respectively). However, one should consider the impact of the baby's lung maturity on the success of extubation. The number of preterm patients in the study group (5/9 babies were premature) was more than the control group (4/10).

It should also be noted that one patient in the study group had a successful cot-side primary reduction under sedation; without general anaesthesia. This patient didn't need any post-operative ventilation. This signifies the value of this technique that; in the right patient and with the proper sized patch, SUC closure technique provides almost a tension free primary reduction compared to direct fascial closure technique.

According to one meta-analysis, eight studies compared the number of days on ventilation between flap and fascial closure cohorts. There were $13.4 \%$ of flap patients in Emami et al. and $40 \%$ of the same cohort in Dariel et al. that completely avoided intubation. For pooled estimates, with 698 included patients in this meta-analysis, the number of ventilation days was 2.6 days less in the flap group when compared to the fascial group. ${ }^{(12)}$.

In the current study, time-to-start (8-11 days vs 6-9 days) or achieve goal enteral 
feeding (14-48 days vs 13-34 days) was longer in patients with SUC patch technique compared to the control techniques respectively, these differences failed to reach statistical significance.

When comparing flap vs fascial closure in literature, a recent meta-analysis revealed the time on TPN to be shorter in the flap closure by 3.9 days $^{(12)}$, but this difference failed to reach statistical significance. Machida et al. also demonstrated significantly fewer days of NPO (nothing per os) in the flap group ${ }^{(13)}$.

In our study, no statistically significant differences were found between the patients of both groups regarding the incidence of the different surgical complications. Two patients in the SUC patch group needed relaparotomy after development of abdominal hypertension. Intestinal obstruction occurred in SUC patch group patient who developed abdominal hypertension and underwent subsequent staged closure; and in another patient in the control group who developed adhesive obstruction at 3 months of age that required a laparotomy.

On the follow up of the patients in the study group, the observed umbilical hernia after the umbilical cord fell had gradually closed by the fifth month in 2 patients and persisted in 1 patient at 6 months follow up. One patient in the control group had a persistent umbilical hernia that required surgical repair at 6 years of age.

In this study, we performed transformation of gastroschisis into a surgically artificial omphalocele, where the inner surface of the umbilical stump was engrafted onto the intestine. This patch is a 'safety valve', and in addition to the augmentation of the abdominal cavity it may prevent many well-known complications. Our procedure is suitable for patients with not so large viscera abdominal disproportion, peel, atresia, and a narrow gastroschisis defect. This patch prevents adhesion with the underlying bowel, and separation and tearing of the patch have never been recorded. The umbilical patch proved to be solid, and any kind of strengthening during the procedure was not needed.

\section{Wharton's jelly stem cells in gastroschisis repair}

Zivkovic SM et al. recently published a paper where they described their long-term results with the inner surface of the umbilical cord (ISUC), and the effect of WJ on the functional and esthetic appearance of the umbilical area after the reconstruction of gastroschisis. They also compared it with conservatively managed omphalocele and gastroschisis reduction using umbilical cord capping. Twenty-one patients with gastroschisis were treated with this technique from 1986 to $2003^{(14)}$.

Zivkovic SM et al. proved in their study that WJ cells possess ultrastructural characteristics of both fibroblasts and smooth muscle cells, indicating that they are modified, rather than being typical fibroblasts. Their objective was to prove the vitality and durability of the US after delivery using Eagle's medium for tissue culture.

\section{Strengths and limitations}

- Our study is a multi-institutional study carried out in 2 tertiary paediatric surgical centres; NNYH in the UK and ASUH in Egypt. However, this had the limitation of the variability of the practice and resources between the 2 centres. The authors however tried to unify the management protocols in both institutes.

- Our study was performed by a single well-trained experienced surgeon in each of the two centres; both of which is a well-equipped university hospital, and this adds to the validity of the results. 
However, it is difficult to apply the results in to the wide clinical practice.

- Gastroschisis is not a common congenital anomaly; occurring only in $1 / 4000$ live births. This made the recruitment of the patients in the study a difficult process. This eventually led to a small sample size and hence not all the results were statistically significant.

- The current study is the first study to compare the results of primary closure of gastroschisis using a SUC patch versus direct fascial closure. However; in order to validate the results and generalise the use of the technique, another study (preferably a randomised control trial) with a bigger sample size needs to be carried out in order to achieve a better level of evidence.

- The duration of the follow up for the patients in the study group was not long enough to validate the long-term outcomes of the new technique. This can be justified due to the pilot nature of the study, rarity of the disease and the relatively short study duration. A more long-term follow up for patients in the study group is needed to validate the safety and efficacy of the technique.

\section{Conclusion}

Primary closure of gastroschisis using SUC is safe, feasible, cost-effective and with comparable outcomes when compared to other well-established techniques. This is of special importance in low resource settings where preformed silos are not available.

The main value of SUC technique that it combines the advantages of primary fascial closure technique (which is better as regard the length of hospital stay and more rapid establishment of enteral feeds) and staged closure using preformed silo (with its published advantage of reduced ventilation and general anesthesia requirements).

\section{REFERENCES:}

1. Feldkamp ML, Carey JC, and Sadler TW: Development of gastroschisis: Review of hypotheses, a novel hypothesis, and implications for research. Am J Med Genet A 2007; 143: pp. 639-65

2. Calder J.: Two examples of children born with preternatural conformations of the guts. Med Essays Observations Edinb 1733; undefined: pp. 203-204

3. Hey W.: In (eds): Practical observations in surgery. London: Cadell and Davis, 1803. pp. 228

4. Vissick C. An umbilical hernia in a newly born child. Lancet 1873; 1:829.

5. Baird PA, and MacDonald EC: An epidemiologic study of congenital malformations of the anterior abdominal wall in more than half a million consecutive live births. Am J Hum Genet 1981; 33: pp. 470-47

6. Bradnock TJ, Marven S, Owen A, et al. Gastroschisis: one-year outcomes from national cohort study. BMJ 2011;343: d6749.

7. Erdoğan D, Azılı MN, Cavuşoğlu YH, et al. 11-year experience with gastroschisis: factors affecting mortality and morbidity. Iran J Pediatr 2012; 22:339-43.

8. Feldkamp ML, Carmichael SL, Shaw GM, et al: Maternal nutrition and gastroschisis: Findings from the National Birth Defects Prevention Study. Am J ObstetGynecol 2011; 204: pp. 404

9. Zani A, Ruttenstock E, Davenport M, et al. Is there unity in Europe? First survey of EUPSA delegates on the management of gastroschisis. Eur J Pediatr Surg 2013; 23:19-24.

10. Bradnock TJ, Marven S, Owen A, Johnson P, Kurinczuk J, Spark P. et al. British Medical Journal. 2011; 343: 01-09.

11. Owen A, Marven S, Jackson L, Antao B, Roberts $\mathrm{j}$, Walker J. et al. Experience of bedside preformed silo staged reduction and closure for gastroschisis. Journal of Paediatric Surgery. 2006; 41:1830-35 
12. Fouad Youssef, Andrew Gorgy, Ghaidaa Arbash, Pramod S. Puligandla, Robert J. Baird. Flap versus fascial closure for gastroschisis: a systematic review and metaanalysis. Journal of Pediatric Surgery 51 (2016) 718-725.

13. MachidaM, Takamizawa S, Yoshizawa K, et al. Effectiveness of sutureless abdominal wall closure for gastroschisis. Shinshu Med J 2013; 61:27-31.
14. S. Zivkovic, M. Djordjevic, B. Stojanovic et al. Effectiveness of Wharton's jelly stem cells in gastroschisis repair using the inner surface of the umbilical cord as a patch: long-term results. Annals of Pediatric Surgery 2015, 11:173-180

15. Clavé H, Niccolai P. Painless hysterectomy: an innovative technique. Journal de gynecologie, obstetrique et biologie de la reproduction. 2003 Jun;32(4):375-80. 


\section{Sherif M Mansour, et al.,}

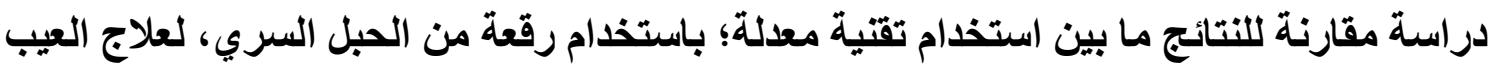

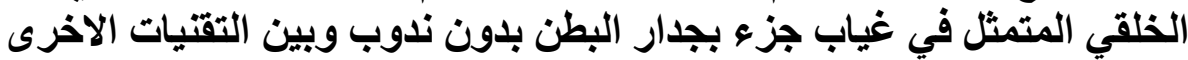

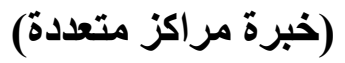

شريف منصور *و أسامة النجارثو توماس تسانج**و مسعد البحيري*و محمد الابيكي و محمد الثربيني*

المقدمة: إن الهدف من الإدارة الجراحية لألم المعدة هو إعادة الأمعاء إلى البطن دون تعريض الأحشاء للخطر. الإغلاق اللفافي الأولي كان يفضل تاريخيا بسبب تحسن الإن النتائج.

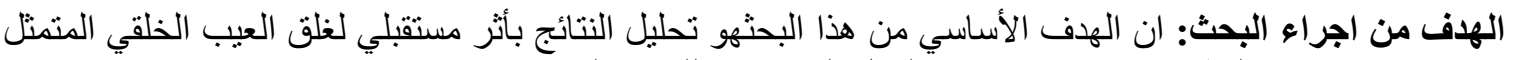

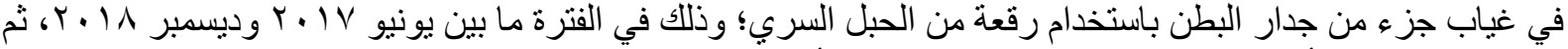
مقارنة هذه النتائج بأثر رجي بار بالنتائج باستخدام التقنيات الأخرى.

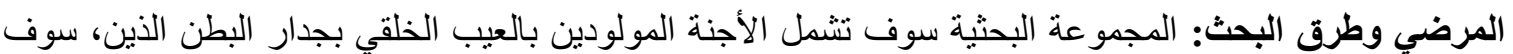

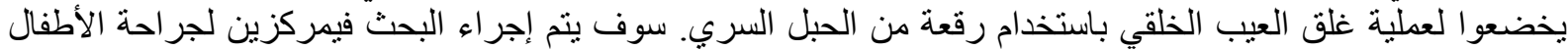

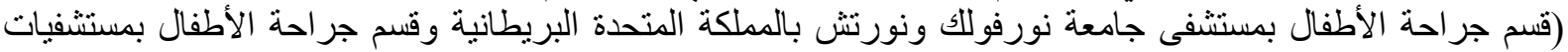

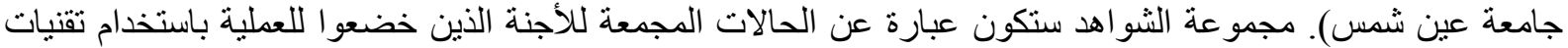

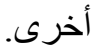

$$
\text { التقنية الجراحية: يتم تحضير رقعة الحبل السري كالآتي: }
$$

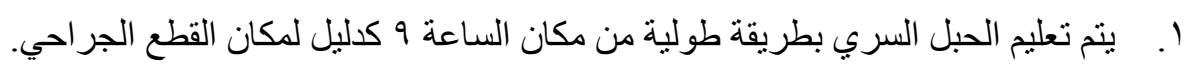

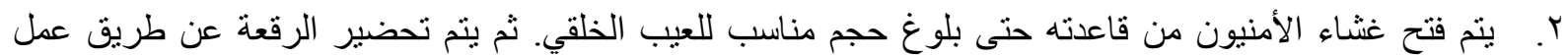
فتحات طولية مع الحفاظ على الأو عية الدموية لللسرة.

r. وبعد ذلك يتم تثبيت الرقعة على مكان العيب الخلقي، باستخدام الغرز الجر احية المنفصلة.

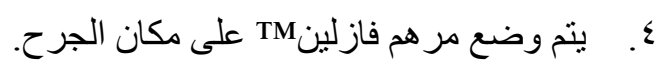

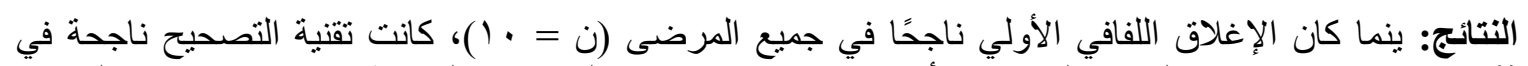

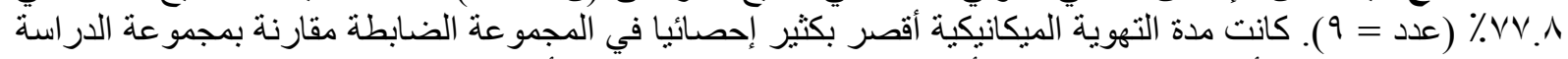

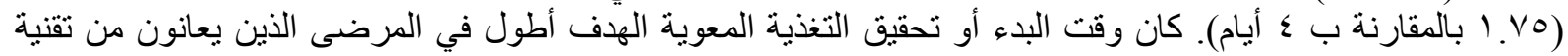

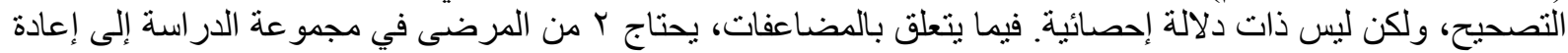

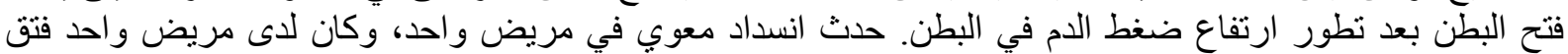

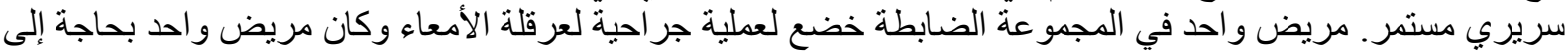
إصلاح فتق سري. الاستتناج: لإغلاق الأولي للأزمة المعدية باستخدام رقعة من الحبل السري طريقة آنذة، وفعالة من حيث التكلفة، مع نتائج ممائلة لأساليب أخرى. 